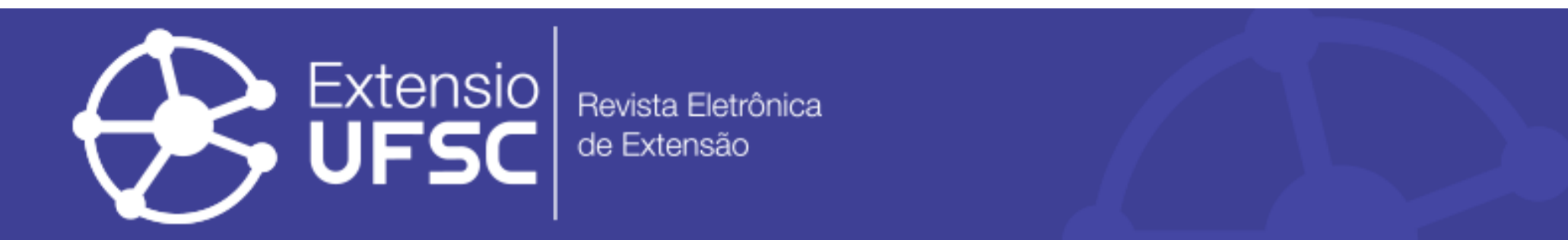

\title{
ANÁLISE DE INTERAÇÕES CIÊNCIA-TECNOLOGIA-SOCIEDADE (CTS) E DE NÍVEIS DE ALFABETIZAÇÃO CIENTÍFICA EM UMA ATIVIDADE EXTENSIONISTA
}

\author{
Ruth do Nascimento Firme \\ Universidade Federal Rural de Pernambuco \\ ruthquimica.ufrpe@gmail.com
}

\author{
Jonas João do Nascimento \\ Universidade Federal Rural de Pernambuco \\ jonasnb94@gmail.com
}

\begin{abstract}
Resumo
Neste trabalho os objetivos são analisar interações Ciência-Tecnologia-Sociedade (CTS) e identificar níveis de alfabetização científica em uma intervenção extensionista desenvolvida no âmbito do projeto de extensão Letramento Científico e Tecnológico em Escolas Públicas: discutindo interações CTS através de episódios do seriado Os Simpsons, desenvolvido em 2017 e apoiado pela Pró-Reitoria de Atividades de Extensão (PRAE) da Universidade Federal Rural de Pernambuco. A atividade extensionista em tela abordou a temática Radioatividade por meio do episódio "Holmer, o fazendeiro", contou com a participação de 13 alunos da $3^{\text {a }}$ série do ensino médio, e foi realizada no auditório de uma das escolas com duração de duas aulas de 50 minutos cada. Os dados considerados para as análises foram as discussões dos alunos durante o debate, registradas em caderno de notas pelo bolsista de extensão e as respostas dos alunos ao questionário impresso. Os resultados das análises indicam que a intervenção extensionista possibilitou discussões sobre diferentes interações CTS e oportunizou aos alunos elementos para a alfabetização científica prática e cultural. Contudo, outras estratégicas metodológicas precisam ser redesenhadas com vistas à alfabetização científica cívica.
\end{abstract}

Palavras-chave: Atividade Extensionista. Interações CTS. Níveis de Alfabetização Científica.

\section{ANALYSIS OF INTERACTIONS STS AND LEVES OF SCIENTIFIC AND TECHNOLOGICAL LITERACY IN AN EXTENSIONIST ACTIVITY}

\begin{abstract}
In this work the objectives are to analyze Science-Technology-Society interactions (STS) interactions and to identify levels of scientific literacy in an extensionist intervention developed within the scope of the extension project Scientific and Technological Literature in Public Schools: discussing interactions CTS through episodes of the series The Simpsons, developed in 2017 and supported by the Pro-Rectory of Extension Activities (PRAE) of the University Federal Rural of Pernambuco. The extensionist activity on screen covered the theme Radioactivity through the episode "Holmer, the farmer", had the participation of 13 students of the third grade of high school, and was held in the auditorium of one of the schools lasting two classes of 50 minutes each. The data considered for the analyzes were the discussions of the students during the debate, registered by the extension student in the notebook and the students' responses to the questionnaire printed. The results of the analyzes indicate that the extensionist intervention enabled discussions about different CTS interactions and gave the students elements for practical and cultural scientific literacy. However, other methodological strategies need to be redesigned for civic scientific literacy.

Keywords: Extensionist Activity. Interactions STS. Levels of Scientific Literacy.

\section{ANÁLISIS DE INTERACCIONES CTS Y NIVELES DE LETRAMIENTO CIENTÍFICO Y TECNOLÓGICO EN UNA ACTIVIDAD EXTENSIONISTA}

\section{Resumen}

En este trabajo los objetivos son analizar interacciones Ciencia-Tecnología-Sociedad (CTS) e identificar niveles de alfabetización científica en una intervención extensionista desarrollada en el ámbito del proyecto de extensión. Lector Científico y Tecnológico en Escuelas Públicas: discutiendo interacciones CTS a través de episodios de la serie Los Simpsons, desarrollado en 2017 y apoyado por la Pro-Rectoría de Actividades de Extensión (PRAE) de la Universidad Federal Rural de Pernambuco. La actividad extensionista en pantalla abordó la temática Radioactividad por medio del episodio "Holmer, el granjero", contó con la participación de 13 alumnos de la tercera serie de la enseñanza media, y fue realizada en el auditorio de una de las escuelas con duración de dos clases de 50 minutos cada uno. Los datos considerados para los análisis fueron las discusiones de los alumnos durante el debate, registradas por el becario de extensión en cuaderno de notas y las respuestas de los alumnos al cuestionario impreso. Los resultados de los análisis indican que la intervención extensionista posibilitó discusiones sobre diferentes interacciones CTS y oportunizó a los alumnos elementos para la alfabetización científica práctica y cultural. Sin embargo, otras estratégicas metodológicas necesitan ser rediseñadas para la alfabetización científica cívica.

Palavras clave: Actividad Extensionista. Interacciones CTS. Niveles de Alfabetización Científica. 
Análise de interações Ciência-Tecnologia-Sociedade (CTS) e de níveis de alfabetização científica em uma atividade extensionista

\section{INTRODUÇÃO}

Os objetivos neste trabalho são os de analisar interações Ciência-Tecnologia-Sociedade (CTS) e identificar níveis de alfabetização científica em uma intervenção extensionista, desenvolvida com alunos da $3^{a}$ série do ensino médio no âmbito do projeto de extensão Letramento Científico e Tecnológico em Escolas Públicas: discutindo CTS através de episódios do seriado "Os Simpsons".

Estes objetivos são justificados considerando que as interações CTS estão presentes no cotidiano de grande parte da sociedade contemporânea. Por exemplo, apesar da ciência e da tecnologia terem naturezas diferentes, estão cada vez mais interdependentes à medida que "a ciência cria novos objetos técnicos e a técnica cria novas linhas de objetos científicos" (SANTOS, 1999, p. 148).

Adicionalmente, ainda segundo Santos (1999, p. 149-150), dificilmente a ciência e a tecnologia podem ser pensadas como externas ao contexto da sociedade considerando que "os impactos culturais, éticos, filosóficos, políticos, econômicos e educacionais dos desenvolvimentos científico e tecnológico [...] e os da sociedade na ciência, [...], são tão amplos, [...] que não podemos permanecer alheios" e que a sociedade tanto impulsiona o desenvolvimento da tecnologia como a tecnologia interfere na sociedade.

É nesse contexto que situamos a relevância da alfabetização científica e tecnológica (ACT) dos cidadãos, entendida neste trabalho como o "saber ler a realidade, uma realidade concreta marcada pelo desenvolvimento científico e tecnológico" (MARCO-STIEFEL, 2001, p. 34) (tradução nossa). Portanto, a necessidade de cidadãos alfabetizados científica e tecnologicamente se justifica considerando que, segundo Marco-Stiefel (2001), estes precisam entender o mundo em que vivem para nele poder intervir com vistas ao bem de todos.

Aikenhead (2009, p. 20) aponta que um cidadão cientificamente alfabetizado "compreende como a ciência e a tecnologia colidem com a vida pública. Embora esta compreensão seja enriquecida por um conhecimento substancial da ciência, não passa só por este conhecimento".

Historicamente, o conceito de alfabetização científica surgiu nos séculos XIX e XX com o objetivo de ensinar a leitura e a escrita para uma população que estava à margem do progresso cultural e social (ALONSO, 2010). Porém, com o desenvolvimento científico e tecnológico ao longo do século XX "novas necessidades culturais para os cidadãos do século XXI que estão destinados a viverem rodeados de C e T nas sociedades do conhecimento" (ALONSO, 2010, p. 49) estão surgindo, como, por exemplo, a ACT. 
Análise de interações Ciência-Tecnologia-Sociedade (CTS) e de níveis de alfabetização científica em uma atividade extensionista

Nessa direção, neste trabalho assume-se o pressuposto de que uma das formas de contribuir para a ACT dos indivíduos é propiciar aos mesmos a compreensão de interações entre ciência, tecnologia e sociedade. Portanto, corroborando com Santos (1999, p. 202), entende-se que é "a necessidade da compreensão de questões sociais relacionadas com a ciência e com a tecnologia que exige que pessoas sejam científica e tecnologicamente alfabetizadas".

Marco-Stiefel (2001) apresenta níveis desejáveis de alfabetização científica, de complexidade crescente, que se diferenciam por seus conteúdos no atendimento a determinados conhecimentos e habilidades para o exercício da cidadania. São eles: a alfabetização científica prática, relativa ao uso de conhecimentos científicos em situações comuns do dia-a-dia; a alfabetização científica cívica, relativa aos níveis de intervenção com critério científico em decisões políticas, debates sociais, entre outros; e a alfabetização científica cultural, a qual além de atingir os níveis de alfabetização anteriores, avança no sentido de considerar o que é a ciência, o que é tecnologia, como estas se relacionam e como incidem na configuração e na dinâmica da sociedade, ou seja, na compreensão, por exemplo, de diversas "interações da ciência com outros campos, suas repercussões humanas, seus modos próprios de construção [...]” (MARCOSTIEFEL, 2001, p. 39) (tradução nossa). Portanto, segundo Marco-Stiefel (2001), a alfabetização científica e tecnológica demanda por mudanças metodológicas no processo de ensino e requer uma aprendizagem em contexto que apresente cenários da ação da ciência e da tecnologia.

Um aspecto a ser destacado refere-se à discussão entre os termos alfabetização e letramento. Segundo Soares (1998, p. 47) o termo alfabetizado refere-se à ação de ler e escrever e o termo letrado a um "estado ou condição de quem não apenas sabe ler e escrever, mas cultiva e exerce práticas sociais que usam a escrita". Nessa direção, para Santos (2007), o termo letramento científico e tecnológico é mais apropriado, visto que, este compreende leitura e compreensão da ciência, expressão de opiniões sobre ciência, preocupação com os problemas da ciência contemporânea, participação nas tomadas de decisão democráticas e compreensão de como ciência, tecnologia e sociedade se influenciam mutuamente. Portanto, considerando as discussões de Marco-Stiefel (2001) sobre a alfabetização científica e a compreensão de letramento científico assumida por Santos (2007), adotamos neste trabalho o termo alfabetização e o termo letramento em uma mesma perspectiva.

A luz das discussões apresentadas, este trabalho é conduzido pela seguinte questão de pesquisa: quais interações CTS são discutidas em uma intervenção extensionista, desenvolvida com alunos da $3^{\text {a }}$ série do ensino médio no âmbito do projeto de extensão Letramento Científico e Tecnológico em Escolas Públicas: discutindo interações Ciência-Tecnologia-Sociedade (CTS) 
Análise de interações Ciência-Tecnologia-Sociedade (CTS) e de níveis de alfabetização científica em uma atividade extensionista

através de episódios do seriado Os Simpsons, e quais níveis de alfabetização científica podem ser identificados nesse processo?

\section{MATERIAIS E MÉTODOS}

Este estudo é uma das ações do projeto de extensão desenvolvido em 2017, apoiado pela Pró-Reitoria de Atividades de Extensão (PRAE) da Universidade Federal Rural de Pernambuco (UFRPE), e conduzido por um licenciando em Química desta IES, bolsista da extensão.

Duas escolas públicas do entorno da UFRPE foram convidadas para o desenvolvimento do projeto. Por conseguinte, a partir do aceite das escolas em participar, o projeto foi desenvolvido com a participação de alunos da $3^{a}$ série do ensino médio das escolas públicas e teve como objetivo contribuir para a inserção de discussões sobre interações CTS em escolas públicas da Região Metropolitana do Recife visando o letramento científico e tecnológico dos alunos.

A escolha da série de TV como um dos recursos didáticos para o desenvolvimento do projeto de extensão em tela justifica-se pelo fato de que a "exibição e discussão de filmes relacionando a produção e os produtos científicos com o cotidiano de pessoas [...]" é uma das possibilidades para contextualização de conteúdos escolares e motivação dos estudantes (LEAL, 2009, p. 79). Adicionalmente, o seriado Os Simpsons foi escolhido a partir do momento que conhecemos o livro Os Simpsons e a Ciência: o que eles podem nos ensinar sobre física, robótica, a vida e o universo, de Paul Halpern. Segundo este autor,

[...]. É raro um desenho de televisão desencadear uma discussão intelectual ou gerar artigos publicados. Contudo, Os Simpsons inspiraram publicações sobre cuidados médicos, psicologia, evolução e outros temas. É uma série vista por muitos cientistas e, portanto, escrutinada quanto a sua veracidade e implicações de uma maneira sem precedentes (HALPERN, 2012, p. 23).

No respectivo projeto de extensão, foram desenvolvidas as seguintes etapas metodológicas: estudo e análise de episódios do seriado Os Simpsons quanto às interações CTS; visitação às escolas para a apresentação do projeto de extensão; visitação às escolas para definição do cronograma de desenvolvimento do projeto de extensão; desenvolvimento do projeto de extensão nas escolas; elaboração de trabalhos para participação em congressos, eventos de extensão e para publicação em periódicos da área de extensão; elaboração de relatórios parciais e final; e avaliação do projeto de extensão. 
Análise de interações Ciência-Tecnologia-Sociedade (CTS) e de níveis de alfabetização científica em uma atividade extensionista

Após o estudo e análise dos episódios do seriado disponíveis na internet, oito deles foram selecionados: Os genes dos Simpsons; Holmer, o fazendeiro; Blinky, o peixe de três olhos; O brilho radiante de Burns; A receita de Lisa para a vida; Comoção perpétua; Mergulho terra abaixo; e A odisseia espacial de Holmer. É relevante ressaltar que estes episódios estão no livro Os Simpsons e a Ciência de Paul Halpern.

No desenvolvimento deste projeto de extensão, oito intervenções extensionistas foram realizadas mensalmente pelo bolsista de extensão de abril a novembro de 2017 , cada uma delas abordando um episódio do respectivo seriado. Para este trabalho específico, optamos pela segunda intervenção extensionista desenvolvida em uma das escolas participantes do projeto, visto que na primeira os alunos ainda estavam se adaptando à metodologia do projeto de extensão em desenvolvimento. Nesta intervenção foi trabalhado o episódio "Holmer, o fazendeiro" e uma de suas cenas está ilustrada na figura 1.

Com duração de duas aulas de 50 minutos cada, a segunda intervenção teve início com a apresentação da temática Radioatividade aos 13 alunos da $3^{\text {a }}$ série do ensino médio de uma das escolas por meio da exibição do respectivo episódio em data show no auditório da escola.

Em seguida, após a exibição, o debate foi aberto a partir da seguinte questão para os alunos: o que é radiação? Após as discussões sobre a radiação, os alunos foram solicitados a responderem um questionário impresso com as seguintes questões: 1) Seria possível uma plantação assim?; 2) Qual o impacto social que este fruto poderia causar?; 3) Esse impacto seria negativo ou positivo?; 4) O que é o Plutônio, elemento utilizado por Homer para preparação da terra? Após os alunos responderem o questionário, estes foram entregues ao bolsista de extensão responsável pela execução do projeto.

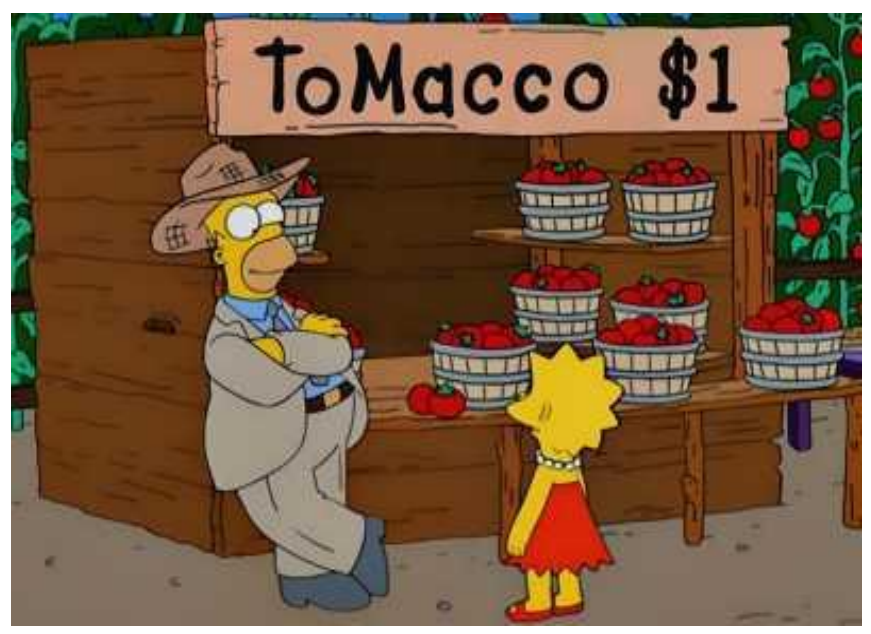

Figura 1: Os Simpsons: temporada 11, episódio 5, Homer - O Fazendeiro

Fonte: https://mi.tv/br/programas/os-simpsons-s11e05-homer-o-fazendeiro 
Análise de interações Ciência-Tecnologia-Sociedade (CTS) e de níveis de alfabetização científica em uma atividade extensionista

O registro da discussão com os alunos durante o debate sobre radiação no caderno de campo do bolsista gerou dados para as análises das interações CTS discutidas na atividade extensionista em tela. E as respostas escritas pelos alunos no questionário impresso foram os dados levados em consideração para as análises dos níveis de alfabetização científica dos mesmos.

Para as análises das interações CTS foram consideradas como categorias analíticas: as interações CTS (interações CT, interações CS e interações ST) na perspectiva discutida por Santos (1999). Para as análises dos níveis de alfabetização científica foram consideradas como categorias: alfabetização científica prática, alfabetização científica cívica e alfabetização científica cultural (MARCO-STIEFEL, 2001).

\section{RESULTADOS E ANÁLISES}

Para apresentação dos resultados e análises, inicialmente o episódio "Holmer, o fazendeiro" é descrito. Em seguida, interações CTS são analisadas com base nas respostas dos alunos ao debate sobre o que é radiação. Posteriormente, analisamos respostas escritas dos alunos ao questionário impresso para a identificação de níveis de alfabetização científica dos mesmos a partir da intervenção extensionista desenvolvida.

Neste episódio, Holmer, após desafiar um coronel para um duelo, se arrepende e foge com a família para a antiga fazenda do vovô. Holmer inicia então a atividade de agricultor e vai ao armazém local comprar ferramentas e sementes. Sem perceber, ele compra uma porção de sementes de tomate e outra porção de semente de tabaco. Holmer semeia as porções na terra da fazenda. Mas, após um mês, as sementes não se desenvolvem. Desesperado com a situação, Holmer buscando uma porção mágica para que as sementes cresçam, faz uma encomenda de plutônio. Quando o produto chegou, ele usou em toda a plantação. No dia seguinte, Holmer, tendo o conhecimento de que a radiação faz as coisas cresceram rapidamente, acorda com grandes expectativas quanto à sua abundante radioativa colheita. E como o esperado, surgiu uma vigorosa plantação de um fruto parecido com tomate, cujo gosto parecia com o de cigarro e sua coloração interior era marrom. Lisa, filha de Holmer, pressupõe que as sementes de tomate germinaram junto com as de tabaco. Holmer, entusiasmado com sua produção, denomina o fruto de tomacco e começa a vender o fruto na beira da estrada. A venda é um sucesso, pois o fruto tem efeito viciante para as pessoas, pois quanto mais comiam, mais queriam comer. Vendo o sucesso das vendas, a companhia de tabaco Laramie propõe uma parceria bilionária para os 
Análise de interações Ciência-Tecnologia-Sociedade (CTS) e de níveis de alfabetização científica em uma atividade extensionista

Simpsons, e estes por sua vez perdem a parceria ao exigir uma quantia muito maior do que a oferecida. Por um descuido de Holmer, os animais comeram o restante da plantação do tomacco e ficaram viciados pelo fruto. As coisas se complicam quando o último pé de tomacco é roubado pela companhia de tabaco citada, mas este, acidentalmente, é destruído. Por fim, Holmer e sua família voltam para Springfield.

A partir da descrição do respectivo episódio, é observada a possibilidade de discussão de diferentes interações CTS ao longo da intervenção extensionista. Neste sentido, como foi mencionado anteriormente, após a exibição do episódio, foi colocada para os alunos a seguinte questão: o que é radiação?

A partir deste questionamento, um debate foi aberto e de acordo com o registro da discussão com os alunos sobre o que é radiação, no caderno de campo do bolsista, diferentes aspectos sobre radiação foram discutidos entre o professor da disciplina, o bolsista de extensão responsável pela execução do projeto, e os alunos da escola, como, por exemplo: a radiação presente no cotidiano considerando forno de micro-ondas, aparelhos hospitalares, (interações CTS); usinas de energia nuclear e o uso do urânio para produção de plutônio (substância radioativa abordada no episódio) (interações CT); impactos ambientais e sociais do funcionamento das usinas nucleares considerando tipos de resíduos nucleares (interações ST); a geração de energia limpa para a sociedade e a necessidade de conscientização das pessoas acerca destes aspectos (interações CTS).

Tais discussões corroboram as ideias de Santos (1999) ao mencionar que o desenvolvimento científico e tecnológico impacta a sociedade em diversos aspectos, como, por exemplo, pelos impactos positivos e negativos do funcionamento de uma usina nuclear, e que a sociedade, por sua vez, impacta no desenvolvimento da ciência e da tecnologia, como, por exemplo, por meio de debates sociais organizados diante dos impactos ambientais decorrentes do uso da radiatividade.

Para além das interações CTS identificadas no momento do debate com os alunos sobre radiação, outros aspectos poderiam ser discutidos a partir do episódio abordado na atividade extensionista em tela. Considerando especificidades deste episódio apresentado aos alunos, a discussão poderia ser direcionada, por exemplo, para os isótopos radiativos (C) no contexto do uso de traçadores radioativos $(\mathrm{T})$, caracterizando interações CT. Adicionalmente, aspectos sociais $(\mathrm{S})$ relativos à radiatividade $(\mathrm{C})$ e ao uso de traçadores radioativos $(\mathrm{T})$ poderiam ser discutidos, considerando, por exemplo, o uso de traçadores radiativos em diferentes áreas como medicina e agricultura, bem como questões econômicas e desvantagens envolvidas neste processo (S), caracterizando interações CS e interações TS. 
Análise de interações Ciência-Tecnologia-Sociedade (CTS) e de níveis de alfabetização científica em uma atividade extensionista

Portanto, partindo do pressuposto de que uma das formas de contribuir para a ACT dos indivíduos é propiciar aos mesmos a compreensão de interações CTS, pode-se dizer que a intervenção extensionista analisada possibilitou aos alunos, a partir da abordagem do episódio "Holmer, o fazendeiro" e das discussões realizadas no debate, a compreensão de interações CTS em diferentes perspectivas, como, por exemplo, interações CT (relativas ao funcionamento de usinas de energia nuclear a partir de reações nucleares), interações CS (relativas à radiação presente no cotidiano) e interações ST (referentes aos impactos ambientais e sociais do funcionamento das usinas nucleares).

Após o debate com os alunos sobre a radiação, todos eles foram solicitados a responderam um questionário com quatro questões, conforme mencionado na metodologia. Quanto à primeira questão (Seria possível uma plantação assim?) dos treze alunos, sete responderam que não, apresentando justificativas tais como, a destruição do solo pelo material radioativo, a falta de relatos sobre o fato, e o fato do plutônio, sendo uma substância radioativa, destruir o solo e os vegetais, conforme podemos perceber a partir da transcrição das respostas de alguns dos alunos: "Não, pois o plutônio 'destruiria' completamente o solo e os vegetais" (Aluno A) e "Não, porque a radiação iria destruir o solo" (Aluno B).

Entretanto, seis alunos responderam que sim, e nesse sentido, justificaram suas respostas considerando que: em um local com muita radiação pode crescer plantas geneticamente modificadas, no laboratório essa plantação seria possível e que já existe caso deste tipo em estudos, conforme ilustramos com as respostas transcritas de alguns alunos: "Sim, porque já existe caso" (Aluno C) e "Sim, porque em um local com muita radiação pode crescer plantas geneticamente modificadas" (Aluno D).

Considerando a segunda e terceira questões (Qual o impacto social que este fruto poderia causar? Esse impacto seria negativo ou positivo?), $100 \%$ dos alunos, ou seja, todos os treze, responderam que o impacto seria negativo. Alguns justificaram suas respostas considerando, por exemplo, que o fruto tomacco causaria: vício nas pessoas; grande quantidade de radiação no organismo gerando tumores; problemas de saúde; e doenças, como o câncer. Respostas tais como, "Grande quantidade de radiação no organismo das pessoas que iram comer. Negativo, pois iriam gerar tumores" (Aluno D), "Seria um impacto negativo, pois traria doenças como o câncer devido a radioatividade" (Aluno B) e "Negativo, pois considerando que seja possível, traria enormes problemas de saúde para quem vai digerir por conta da radiação" (Aluno A), são evidências da compreensão deles sobre impactos negativos decorrentes deste processo.

Em relação à quarta questão (O que é o plutônio, elemento utilizado por Homer para preparação da terra?), apenas um dos alunos apresentou uma resposta que não foi adequada ao 
ponto de vista aceito cientificamente: "Plutônio seria uma espécie de nicotina que altera o gosto e a forma e que pode alterar as formas biológicas de vidas por causa da radiação" (Aluno F). Entretanto, os doze outros responderam que o plutônio é uma substância radioativa derivada do urânio. Destes doze, quatro mencionaram ainda que o plutônio, além de ser radioativo, é um metal de transição interna, conforme as transcrições de algumas das respostas dos alunos: "É um material radioativo derivado do urânio" (Aluno B), "Um material altamente radioativo, geralmente utilizado na produção de energia, sendo derivado do urânio" (Aluno A), "O plutônio é um metal de transição interna. Ele é radioativo" (Aluno E) e "É um elemento altamente radioativo derivado do urânio" (Aluno D).

A partir da análise das respostas dos alunos ao questionário, identificamos evidências de dois dos três níveis de alfabetização científica propostos por Marco-Stiefel (2000, 2001), o nível da alfabetização científica prática e o nível da alfabetização científica cultural.

Para primeira questão, sete alunos responderam que não é possível uma plantação com o uso do plutônio e seis responderem que é possível. Para estes dois tipos de respostas, eles consideraram o conhecimento científico, mais especificamente, o conceito de radioatividade, como justificativa. Por exemplo, um dos alunos ao dizer que não seria possível, justificou mencionando que "Não, pois o plutônio 'destruiria' completamente o solo e os vegetais" (Aluno A). Ao expressarem as justificativas, eles estavam se posicionando e tomando a decisão sobre ser possível ou não o uso do plutônio nas plantações considerando, por exemplo o conceito de radiação. E este resultado pode ter estreita relação com o fato de $92,3 \%$ dos alunos expressarem respostas adequadas, do ponto de vista científico, à quarta questão, ou seja, identificarem o plutônio como uma substância radiativa derivado do urânio. Neste sentido, o nível de alfabetização científica prática, aquela na qual se faz uso de conhecimentos científicos em situações comuns do dia-a-dia (MARCO-STIEFEL, 2000; 2001), foi identificado.

As respostas dos alunos para a segunda e a terceira questões, sinalizam indícios ainda que incipientes, que eles poderiam estar caminhando para o nível de alfabetização científica cultural, aquele em se passa a compreender "interações da ciência com outros campos, suas repercussões humanas, seus modos próprios de construção [...]” (MARCO-STIEFEL, 2001, p. 39). Isso porque, em suas respostas todos os alunos apontaram que os impactos sociais da plantação e consumo do fruto produzido na fazenda de Holmer seriam negativos. Fato este que pode ser ilustrado com a transcrição da resposta do aluno B: "Seria um impacto negativo, pois traria doenças como o câncer devido a radioatividade". Portanto, a partir da identificação de respostas semelhantes a esta do aluno B e destacando que $100 \%$ dos alunos responderam que os impactos 
Análise de interações Ciência-Tecnologia-Sociedade (CTS) e de níveis de alfabetização científica em uma atividade extensionista

seriam negativos, eles parecem estar em vias de compreender interações da ciência com outros contextos por meio de impactos sociais decorrentes do uso da radioatividade.

Adicionalmente, as discussões postas aos alunos durante o debate e antes deles serem solicitados a responderem ao questionário, parecem indicar que eles poderiam ter avançado no sentido do nível de alfabetização científica cultural (MARCO-STIEFEL, 2000; 2002). Isso porque naquele momento das discussões, foi oportunizado aos mesmos a percepção, por exemplo, do como o funcionamento de uma usina nuclear pode impactar positivamente ou negativamente a dinâmica da sociedade.

Considerando as respostas dos alunos ao questionário, não foram identificadas evidências que sinalizem aspectos do nível de alfabetização científica cívica, aquele relativo aos níveis de intervenção, com critério científico, em decisões políticas, debates sociais, entre outros (MARCO-STIEFEL, 2000; 2001). A nosso ver este fato tem relação com as questões propostas no questionário. Elas parecem não ter dado conta de ampliar as discussões para este nível de alfabetização científica.

Em síntese, quanto às questões propostas aos alunos no questionário, pode-se dizer que elas, a partir das respostas obtidas, oportunizaram aos mesmos o nível de alfabetização científica prática e do nível de alfabetização científica cultural. Entretanto, entende-se que tais questões não oportunizaram a condução dos alunos no sentido do nível de alfabetização científica cívica.

Portanto, destaca-se a necessidade de que outras estratégicas metodológicas, para além das desenvolvidas na atividade extensionista analisada (debate e proposição de questionário) sejam repensadas e redesenhadas, como, por exemplo, o desenvolvimento de fórum escolar ou participação em consultas públicas on line sobre interações CTS associadas aos temas dos episódios do seriado trabalhados, nas quais os alunos exercitem a participação na tomada de decisão frente às questões sociais relativas à ciência e à tecnologia, de modo a oportunizar aos mesmos os três níveis de alfabetização científica.

\section{CONSIDERAÇÕES FINAIS}

Considera-se que as interações CTS estão presentes no cotidiano de grande parte da sociedade contemporânea, que este contexto demanda por cidadãos científica e tecnologicamente alfabetizados para entenderem o mundo em que vivem, e que a compreensão de interações CTS contribui para a alfabetização científica e tecnológica.

As análises realizadas na identificação de interações CTS discutidas, sinalizam que a intervenção extensionista possibilitou aos alunos, a partir da abordagem do episódio "Holmer, o 
Análise de interações Ciência-Tecnologia-Sociedade (CTS) e de níveis de alfabetização científica em uma atividade extensionista

fazendeiro" e das discussões realizadas no debate sobre radiação, a compreensão de interações CTS em diferentes perspectivas: interações CT (relativas ao funcionamento de usinas de energia nuclear a partir de reações nucleares), interações CS (relativas à radiação presente no cotidiano) e interações ST (referentes aos impactos ambientais e sociais do funcionamento das usinas nucleares).

Quanto aos níveis de alfabetização científica, as análises sinalizaram que a intervenção extensionista oportunizou aos alunos o nível de alfabetização científica prática e do nível de alfabetização científica cultural. Entretanto, esta intervenção não possibilitou a condução dos alunos para o nível de alfabetização científica cívica. O nível de alfabetização científica prática foi identificado à medida que os alunos, para responderem se era possível uma plantação com o uso de plutônio, consideraram o conhecimento científico, mais especificamente, o conceito de radiação, como justificativa para não fazer uso da substância secreta (o plutônio) na plantação de Holmer por esta ser radioativa.

Indícios do nível de alfabetização científica cultural foram identificados, quando todos os alunos apontaram em suas respostas que os impactos sociais da plantação e consumo do fruto produzido na fazenda de Holmer seriam negativos. Ou seja, foi oportunizada aos alunos a compreensão de interações da ciência com outros contextos por meio de impactos sociais decorrentes do uso da radioatividade.

Entretanto, entende-se que a intervenção extensionista analisada não conduziu os alunos ao nível de alfabetização científica cívica. Sobre este aspecto, vale destacar que as questões propostas no questionário parecem não ter dado conta de ampliar as discussões para este nível de alfabetização científica.

Neste sentido, embora a intervenção extensionista tenha oportunizado discussões sobre interações CTS em diferentes perspectivas e a condução dos alunos para níveis da alfabetização científica prática e alfabetização científica cultural, não possibilitou o nível de alfabetização científica cívica. Portanto, considera-se a necessidade de que outras estratégias metodológicas, para além do debate e do uso de questionário, sejam repensadas e redesenhadas, de modo a oportunizar aos alunos avançarem nos três níveis de alfabetização científica.

\section{REFERÊNCIAS}

AIKENHEAD, G. S. Educação científica para todos. Portugal: Edições Pedago, 2009.

ALONSO, A. V. Importância da alfabetização científica e do conhecimento acerca da natureza da ciência e da tecnologia para a formação de um cidadão. Em: M. D. Maciel, C. L. C. Amaral, I. 
Análise de interações Ciência-Tecnologia-Sociedade (CTS) e de níveis de alfabetização científica em uma atividade extensionista

R. B. Guazzelli, Ciência, Tecnologia e Sociedade: pesquisa e ensino. (pp. 43-70) São Paulo: Terracota, 2010.

HALPERN, P. Os Simpsons e a ciência: o que eles podem nos ensinar sobre física, robótica, vida e universo. São Paulo: Novo Conceito Editora, 2008.

LEAL, M. C. Didática da Química: fundamentos e práticas para o ensino médio. Belo Horizonte: Dimensão, 2009.

MARCO-STIEFEL, B. Alfabetización científica y enseñanza de las ciências: estado de la cuestión. Em MEMBIELA, P. Enseñanza de las ciências desde a perspectiva cienciatecnología-sociedad: formación cientifica para la ciudadanía. Madri: NARCEA, S.S DE EDICIONES, 2001.

SANTOS, M. E. V. M. dos. Desafios Pedagógicos para o século XXI: suas raízes em forças de mudança de natureza científica, tecnológica e social. Lisboa: Livros Horizonte, 1999.

SANTOS, W. L. P. dos. Educação científica na perspectiva de letramento como prática social: funções, princípios e desafios. Revista Brasileira de Educação, v. 12 n. 36 set./dez, p. 474-550, 2007.

SOARES, M. Letramento: um tema em três gêneros. Belo Horizonte: Autêntica, 1998.

Recebido em: 12/09/2018

Aceito em: 28/03/2019 